ORIGINAL ARTICLE

\title{
New Zealand national incidence of bronchiectasis "too high" for a developed country
}

\author{
J Twiss, R Metcalfe, E Edwards, C Byrnes
}

See end of article for authors' affiliations

....................

Correspondence to: DrJ Twiss, Starship Childrens' Hospital, Private Bag 92024, Auckland, New Zealand; jacobt@ adhb.govt.nz

Accepted 14 March 2005 Published Online First 4 May 2005

\begin{abstract}
Aims: To prospectively estimate the incidence of bronchiectasis among New Zealand (NZ) children, to consider aetiology and severity, and to evaluate regional and ethnic variation.

Methodology: NZ paediatricians were surveyed monthly for new cases of bronchiectasis during 2001 and 2002 via the NZ paediatric surveillance unit (with coverage of $>94 \%$ of NZ paediatricians). Notified cases had their computed tomography scans reviewed and scored for severity. Confirmed cases were followed up by postal questionnaire one year after diagnosis. Demographic, aetiological, and severity data were collected.

Results: Ninety nine notifications were received. Sixty five cases were confirmed. An overall incidence of 3.7 per 100000 under 15 year old children per year was estimated. Incidence was highest in Pacific children at 17.8 compared with 4.8 in Maori, 1.5 in NZ European, and 2.4 other per 100000 per year. Incidence varied significantly by region. The median age at diagnosis was 5.2 years; the majority had symptoms for more than two years. Eighty three per cent had bilateral disease, with a median of three lobes affected, mean FEV1 of 77\% predicted, and modified Bhalla HRCT score of 18.

Conclusions: The incidence of bronchiectasis is high in NZ children, nearly twice the rate for cystic fibrosis and seven times that of Finland, the only other country reporting a childhood national rate. Incidence varied substantially between ethnicities. Most cases developed disease in early childhood and had delayed diagnosis.
\end{abstract}

$\mathrm{B}$ ronchiectasis is a morphological diagnosis based on dilatation of bronchial airways and is associated with recurrent lower respiratory tract infection, significant morbidity, and mortality. The incidence of bronchiectasis not due to cystic fibrosis (CF) may have fallen in the 20th century with the advent of improved living conditions, vaccination, and antibiotics. However recent reports of high prevalence, morbidity, and mortality within certain communities raises concern..$^{1-6}$ The limited population data that do exist are hard to compare, due to the use of varying denominators and methodologies (including case definitions). Good data are needed to make informed decisions on population health measures, as well as determining the need and direction of future research.

Two national bronchiectasis estimates have recently been reported. In Finland the incidence has been estimated at 0.5 per 100000 children under 15 years in age per year and 3.9 per 100000 per year overall. ${ }^{7}$ In the United States the prevalence has been estimated at 52:100 000 overall and resulted in an additional 1.1 billion US dollars of healthcare expenditure per annum. ${ }^{6}$ Much higher prevalences have been reported in some communities-16:1000 Southwest Alaskan Native children and 15:1000 central Australian Aborigine children. $^{38}$ The impact of bronchiectasis in New Zealand (NZ) has caused concern for some time but data have largely been limited to hospitalisation and mortality data-reported at 50 deaths per 100000 in Maori and Pacific People. ${ }^{10}$ Compared with asthma, a far more common respiratory disease, bronchiectasis causes one tenth the hospital admissions and half the number of deaths. ${ }^{11}{ }^{12}$ It results in $75 \%$ more admissions and nearly five times as many deaths as CF. ${ }^{11}{ }^{12}$ Significant bronchiectasis mortality does not begin until adulthood in NZ, however it is likely that in many cases the disease began in childhood. ${ }^{13}$ A recent report of high prevalence in children living in NZ's largest city (1:6000 overall with 1:1900 Pacific Island children) increases concern. ${ }^{4}$

The aim of this study is to prospectively estimate the national incidence of bronchiectasis diagnoses over a two year period in the 0.85 million NZ children. The study will also identify regional variation, aetiology, and severity.

\section{METHODS}

New cases of bronchiectasis were identified through the NZ Paediatric Surveillance Unit (NZPSU). Each month participating clinicians are sent either a reply paid card or an email (as self nominated) to report new cases of conditions under surveillance. Bronchiectasis was included on the NZPSU Report Card for 2001 and 2002.

\section{Case definition}

- a high resolution computed tomography (HRCT) consistent with bronchiectasis;

$-\leqslant 15$ years of age at HRCT diagnosis;

- productive cough daily for >six weeks or for three months per year for two consecutive years;

- persistent chest $x$ ray abnormalities; and

- not due to cystic fibrosis.

Following notification the referring paediatrician was asked to send the HRCT to the study centre. The case's identity remained anonymous. Diagnosis was confirmed using the radiological criteria of Naidich et $a l^{14}$ and scored using the modified Bhalla by a single paediatric radiologist (RM) with no clinical data. ${ }^{15-17}$ This score has been validated in adult and

Abbreviations: CF, cystic fibrosis; FEVI, forced expiratory volume in one second; HRCT, high resolution computed tomography; NZPSU, New Zealand Paediatric Surveillance Unit. 


\begin{tabular}{ll} 
Table 1 Age, sex, and past history \\
\hline Male:female ratio & $28: 37$ (54\% female) \\
Age at diagnosis & Median 5.2 years (range 0.5-15 \\
& years) \\
Age at onset of cough & Median 2.3 years (range 0-14 \\
& years) \\
Duration of symptoms & Median 1.0 years (range 6 weeks to \\
& 14 years) \\
Age first (non-bronchiectasis) & Median 1.0 years (range 1 month to \\
respiratory hospitalisation (74\%) & 13 years) \\
& $29 \%$ bronchopneumonia \\
& $33 \%$ lobar pneumonia \\
& $38 \%$ bronchiolitis \\
\hline
\end{tabular}

paediatric bronchiectasis and assigns a value to each lobe and the lingula as follows: bronchiectasis extent $(0-3)$, bronchial wall dilatation (0-3) and thickness (0-3), presence of mucus in large (0-1) and small airways $(0-1)$, air trapping (0-4), atelectasis $(0-1)$, and consolidation $(0-1)$ resulting in a worst possible score of $102 .{ }^{15}{ }^{16}$ Postal questionnaires were sent to the paediatrician one year after notification collecting demographic details, investigation results, and ascribed aetiology. The delay was to allow time for investigation without influencing it. Multiple responses were allowed for ethnicity data. ${ }^{18}$ Incidences were calculated using under 15 year old cases for numerators and NZ 2001 census data for denominators. ${ }^{19}$ Pulmonary function is reported as percentage of predicted (Polgar reference). ${ }^{20}$ Prospective ethical approval was gained. Statistical software package SPSS version 11.5 (SPSS Inc, Chicago, IL, USA) was used. Chi square, Kruskal-Wallis, and Spearman $(r)$ were used for nonparametric data; $t$ test and ANOVA for parametric data.

\section{RESULTS}

Ninety nine notifications were received over the two years. Thirty two were excluded due to: duplication/error (10), diagnosis outside the study time period or age range (7), no or non-definitive HRCT (15). Two cases were lost to follow up leaving 65 confirmed cases, 63 under 15 years of age. Half of confirmed notifications came from respiratory specialists and one third from general paediatricians. At diagnosis (median 5.2 years) $40 \%$ of cases had cough for $\geqslant 2$ years (table 1.) The median age of reported symptom onset was 2.3 years. Three quarters had prior hospital admission for other respiratory illness at a median 1 year of age. Only $8 \%$ had no hospital admissions and $18 \%$ were known to have or were diagnosed with bronchiectasis at their first admission. Ninety per cent were NZ born with $5 \%$ born outside the Pacific.

\section{Incidence estimates}

An overall incidence of 3.7 per 100000 under 15 year olds per year is estimated. Incidence varied with ethnicity (1.5-17.8 per 100000 per year, $\mathrm{p}<0.001$; table 2), highest in Pacific

\begin{tabular}{|c|c|c|c|}
\hline Ethnicity & $\begin{array}{l}\text { NZ }<15 \text { year } \\
\text { old population } \\
\text { (multiple choices, } \\
2001 \text { census) }\end{array}$ & $\begin{array}{l}\text { Proportion } \\
\text { of cases }\end{array}$ & $\begin{array}{l}\text { Incidence } \\
\text { (per } 100000 \\
<15 \text { year olds } \\
\text { per year) }\end{array}$ \\
\hline $\begin{array}{l}\text { Pacific } \\
\text { Peoples }\end{array}$ & $11 \%$ & $50 \%$ & 17.8 \\
\hline Maori & $23 \%$ & $30 \%$ & 4.8 \\
\hline NZ European & $73 \%$ & $28 \%$ & 1.5 \\
\hline Other & $8 \%$ & $5 \%$ & $\begin{array}{l}2.4 \\
p<0.001\end{array}$ \\
\hline
\end{tabular}

\begin{tabular}{|c|c|}
\hline Aetiology & $\%(\mathbf{n})$ \\
\hline \multicolumn{2}{|c|}{ Unknown/idiopathic 54 (35) } \\
\hline Post infectious & $\begin{array}{l}22 \text { ( } 6 \text { adenovirus, } 3 \text { pertussis, } 1 \text { tuberculosis, } \\
4 \text { other) }\end{array}$ \\
\hline Post oncology & $\begin{array}{l}11 \text { (5 leukaemia, } 2 \text { lymphoma; } 1 \text { had bone } \\
\text { marrow transplant) }\end{array}$ \\
\hline $\begin{array}{l}\text { Aspiration } \\
\text { Primary } \\
\text { immunodeficiency }\end{array}$ & $\begin{array}{l}6 \text { (3 chronic aspiration, } 1 \text { retained peanut) } \\
6 \text { ( } 4 \text {, all humoral deficiencies) }\end{array}$ \\
\hline
\end{tabular}

children and by region (0-8.3 per 100000 per year, $\mathrm{p}=0.03$; fig 1). More females were reported (37/65 of cases, difference not significant, $\mathrm{p}=0.09$ ).

\section{Aetiology}

Notifiers reported aetiology to be unknown in $54 \%$ of cases, post infectious in $22 \%$, as a result of oncological disease or treatment in $11 \%$, aspiration $6 \%$, and primary immunodeficiency $6 \%$ (table 3 ).

Those of unknown aetiology were older (median $8.3 v 3.6$ years, $\mathrm{p}=0.02)$, had a longer duration of cough $(3.0 \mathrm{v} 1.0$ years, $\mathrm{p}=0.002$ ) and a trend to milder disease (median CT score $14 v 21, \mathrm{p}=0.11$ ). Comorbidities were volunteered (not requested) in 10 cases-prematurity $(8 \%)$, trisomy $21(5 \%)$, congenital heart disease $(2 \%)$, and progressive neuromuscular disease $(2 \%)$.

\section{Pulmonary function}

Ninety per cent $(28 / 31)$ of children aged over 6 years had spirometry. The mean forced vital capacity was $85 \%$ predicted, mean forced expiratory volume in one second

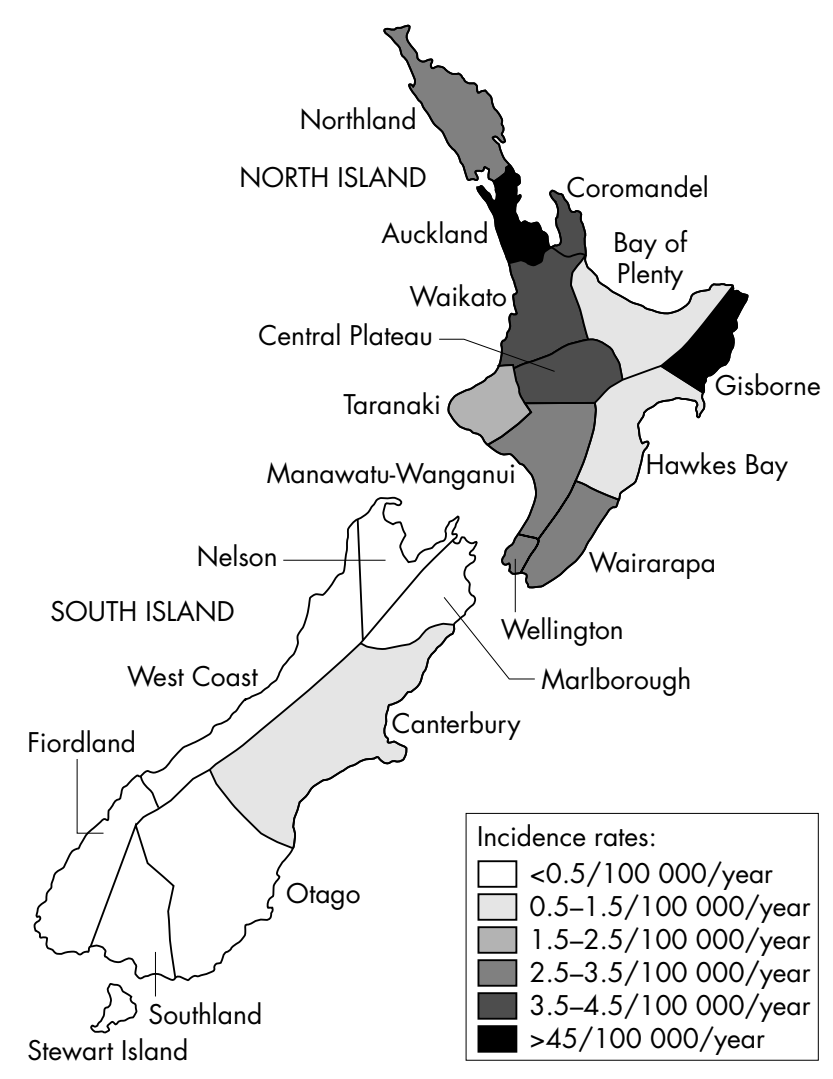

Figure 1 Regional incidence. 


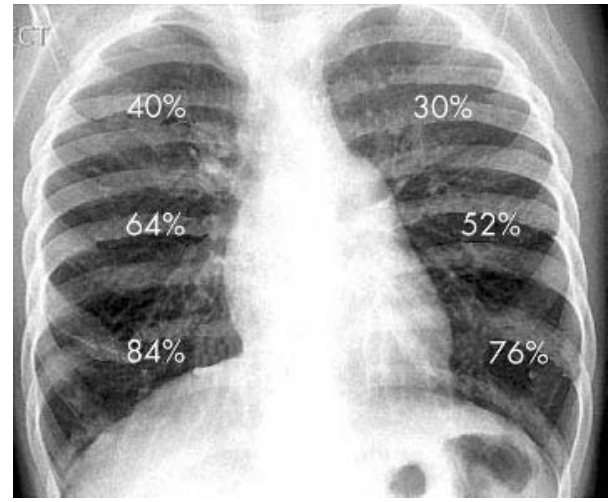

Figure 2 Proportion of cases with each lobe (and lingual) affected.

(FEV1) 77\% predicted, and mean forced expiratory flow 25$75 \%$ of $76 \%$ predicted. Half had an FEVI $<80 \%$ and a quarter $<60 \%$. No difference in lung function was found between sex $(p=0.13)$, ethnicities $(p=0.72)$, or aetiologies $(p=0.62)$.

\section{Radiology}

Eighty three per cent of cases had bilateral bronchiectasis, $61 \%$ had three or more of the five lobes involved and only $16 \%$ had unilobular disease. Lower lobes were most frequently and most severely affected (fig 2). The median modified Bhalla score was 18 (range 4-65) with no significant differences between sex $(p=0.67)$, ethnicities $(\mathrm{p}=0.93)$, aetiologies $(\mathrm{p}=0.47)$, or by age $(r=-0.15)$. The median scores (ranges) for CT score components (sum of lobes) were: bronchiectasis extent, 5 (2-16); bronchial dilatation, 4 (1-16); wall thickness, $2(0-7)$; centrilobular mucus, 0 (0-4); large airway mucus, 0 (0-3); atelectasis, 2 (0-6); and consolidation, $0(0-5)$. FEVl correlated modestly with HRCT score $(r=-0.38, \mathrm{p}=0.04)$.

\section{Investigations}

A full blood count was reported in 97\%, quantitative immunoglobulins in $88 \%$ (30\% elevated, $2 \%$ low), specific antibody responses in $46 \%$, immunoglobulin subclasses in $26 \%$, complement in $25 \%$, and nitrozine blue test in $14 \%$ of cases. Cilia were assessed in $8 \%$ (all normal). Reflux/ aspiration was assessed in $28 \%$ of cases (45\% abnormal). Bacterial respiratory cultures grew Haemophilus influenzae in $48 \%$, Streptococcus pneumoniae in 14\%, Moraxella catarrhalis in $8 \%$, Staphylococcus aureus in $8 \%$, Pseudomonas aeruginosa in 3\%, and were negative/not done in $25 \%$. Cystic fibrosis was not excluded in $27 \%$ of cases; $65 \%$ of these had a definitive aetiology and the remaining were non-European with neither Pseudomonas aeruginosa nor Staphylococcus aureus.

\section{DISCUSSION}

The principle outcome is a minimum incidence of non-CF bronchiectasis in the NZ under 15 year old population of 3.7 per 100000 per year. This rate is seven times higher than the only other comparable national study, 0.49 per 100000 Finnish under 15 year old children, ${ }^{7}$ and equates to one in 1700 births being diagnosed with bronchiectasis before the age of 15 (about twice the CF rate, 1:3179). ${ }^{21}$ If we speculate that the incidence rate is static and that all children with bronchiectasis survive to 15 years of age, then our figure equates to a prevalence of 1:3000 children overall and 1:625 Pacific children.

Ethnic differences in disease incidence, morbidity, and mortality are phenomena of most developed countries. Grant et al reported the Auckland hospitalisation rate for pneumonia was twice as common in Maori and five times as common in Pacific than in NZ European children.22 Pacific and Maori children hospitalised also had more severe pneumonia. ${ }^{23}$ We found the incidence to be three times higher in Maori and 12 times higher in Pacific Peoples compared with those of European ethnicity, but with no differences in severity or aetiology. Nearly $90 \%$ of Pacific children came from Auckland, which holds the largest Polynesian community in the world. Pacific Peoples are not indigenous to NZ but have immigrated in large numbers since World War II. They are a young (median age 21 years) and rapidly growing population with twice the national unemployment rate and are seven times as likely to live in a dwelling with more than two occupants per bedroom. ${ }^{19}$

Assignment of aetiology was made by the referring doctor (unverifiable by the authors) one year after diagnosis. Published case series have variable aetiological distributions as a result of the different criteria used, source populations, and degree of investigation. Over half the cases in this study were of unknown aetiology. The "unknowns" were older, had a longer duration of symptoms, tended to have more investigations, and milder disease (CT score), perhaps a reflection of later presentation and a "colder trail" for causation. Some "unknown aetiology" might have a cause determined with further investigation. Specific antibody assessment, a key element in humoral immunity evaluation, had not been performed in half of the cases. Cilia studies were rarely obtained because of poor availability. All those without a definitive aetiology and not tested for CF were nonEuropean, had normal growth, and did not grow Staphylococcus or Pseudomonas species making CF unlikely. Although NZ has had universal neonatal CF screening since 1982, clinical suspicion still warrants its exclusion. ${ }^{24}$ The significant number of cases in association with oncological disease deserves further review.

This study is limited by its reliance on all cases being diagnosed and then notified. A paediatrician would be expected to be involved in the diagnosis of a child with bronchiectasis and the NZPSU system includes an estimated $94 \%$ of NZ paediatricians. Half the notifications came from respiratory specialists, one third from general paediatricians with no significant differences in aetiology, severity, or investigations found between notifying specialty. Surveillance unit study sensitivity varies by condition but not region or specialty with reported sensitivities of $62-89 \%$ in other NZPSU studies. ${ }^{25}$ Given that respiratory symptoms are common in childhood, and bronchiectasis symptoms are non-specific, a significant proportion of cases are likely to go undiagnosed, particularly in Maori and Pacific Peoples with poorer access to health care. ${ }^{23}$ Fifteen notifications were excluded due to not meeting the HRCT criteria (one not having had a CT); further review and repeat radiology may have confirmed the diagnosis. We believe our incidence figure should be taken as a minimum.

Although one third of cases had cough for $\geqslant 3$ years at diagnosis, children in this study were diagnosed younger and with less delay than reported in the previous Auckland study ${ }^{4}$ and in a recent large UK series, ${ }^{26}$ perhaps reflecting increasing awareness of the disease and earlier referral. However NZ children have more extensive disease than those in overseas case series and the childhood incidence is high, particularly in Pacific children. ${ }^{3-5}$

A decade ago, an NZ Public Health Commission report of the health of NZ Pacific Peoples identified bronchiectasis as a major cause of hospitalisation and the seventh highest cause of death (women). ${ }^{27}$ The Ministry of Health concluded that the report provided a baseline for future monitoring and policy development. ${ }^{28}$ In the same year the NZ Government established child (and Maori) health as "priority gain areas". The results of this study suggest the situation is unlikely to be 


\section{What is already known on this topic}

- Non-CF bronchiectasis, a once common condition, is widely believed to have fallen in incidence since the 19th century.

- Recently high occurrences have been reported within certain communities including Auckland Pacific Island children, south Alaskan Native children, and central Australian Aborigine children.

- International whole population data with which to place these communities in context are lacking. There is only one contemporary published national study in existence reporting an incidence of 0.5 per 100000 Finnish children per year.

\section{What this study adds}

- This is the first prospective national study of bronchiectasis occurrence and is strengthened by requiring both clinical and CT evidence of disease.

- It describes a high minimum incidence in New Zealand children (3.7 per 100000 under 15 year olds per year) with significant regional and ethnic disparity.

- The study provides a baseline for future regional and temporal comparison and has utility in the development of preventative and interventional strategies.

better. If we are to improve, prevention of childhood bronchiectasis must be a priority, and early identification and intervention is vital. We hope this study which documents a high minimum incidence figure, will contribute positively towards that goal.

\section{ACKNOWLEDGEMENTS}

We are indebted to NZ paediatricians, and grateful to the NZPSU, Joan Mary Reynold's Fellowship, and Child Health Research Foundation for their support of this study.

\section{Authors' affiliations}

J Twiss, E Edwards, C Byrnes, Starship Childrens' Hospital, Auckland District Health Board, Auckland, New Zealand

J Twiss, R Metcalfe, E Edwards, C Byrnes, University of Auckland, Auckland, New Zealand

Competing interests: none declared

\section{REFERENCES}

1 Karakoc GB, Yilmaz M, Altintas DU, et al. Bronchiectasis: still a problem. Pediatr Pulmonol 2001;32:175-8.

2 Scala R, Aronne D, Palumbo U, et al. Prevalence, age distribution and aetiology of bronchiectasis: a retrospective study on 144 symptomatic patients. Monaldi Arch Chest Dis 2000;55:101-5.

3 Singleton R, Morris A, Redding G, et al. Bronchiectasis in Alaska Native children: causes and clinical courses. Pediatr Pulmonol 2000;29:182-7.

4 Edwards EA, Asher MI, Byrnes CA. Paediatric bronchiectasis in the twenty first century: experience of a tertiary children's hospital in New Zealand. J Paediatr Chld Hith 2003;39:111-17.

5 Chang AB, Masel JP, Boyce NC, et al. Non-CF bronchiectasis: clinical and HRCT evaluation. Pediatr Pulmonol 2003;35:477-83.

6 Weycker D, Edelsberg J, Oster G, et al. Prevalence and economic costs of bronchiectasis. American Thoracic Society International Conference, May 21-26 2004, Orlando, Florida, USA. Amer J Resp Crit Care Med 2004; 169(7 supplement):330.

7 Säyäjäkangas O, Keistinen T, Tuuponen TO, et al. Evaluation of the incidence and age distribution of bronchiectasis from the Finish Hospital Discharge Register. Cent Eur J Public Health 1998;6:235-7.

8 Chang AB, Grimwood K, Mulholland EK, et al. Bronchiectasis in indigenous children in remote Australian communities. Med J of Australia 2002; 177:200-4.

9 Kolbe J, Wells AU. Bronchiectasis: a neglected cause of respiratory morbidity and mortality. Respirology 1996;1:221-5.

10 O'Neill MKJ, Wells A. Bronchiectasis in New Zealand: a dying disease or neglected epidemic? Am J Respir Crit Care Med 1995;151(A201).

11 New Zealand Health Information Service. Mortality and demographic data 2000: New Zealand Ministry of Health 2004

12 New Zealand Health Information Service. Selected morbidity data for publicly funded hospitals 2000/01, New Zealand Ministry of Health, 2004.

13 Pasteur MC, Helliwell SM, Houghton SJ, et al. An investigation into causative factors in patients with bronchiectasis. Am J Respir Crit Care Med 2000;162:1277-84.

14 Naidich DP, McCauley DI, Khouri NF, et al. Computed tomography of bronchiectasis. J Comput Assist Tomogr 1982;6:437-44.

15 Edwards EA, Metcalfe R, Milne DG, et al. Retrospective review of children presenting with non cystic fibrosis bronchiectasis: HRCT features and clinical relationships. Pediatr Pulmonol 2003;36:87-93.

16 Roberts HR, Wells AU, Milne DG, et al. Airflow obstruction in bronchiectasis: correlation between computed tomography features and pulmonary tests. Thorax 2000;55:198-204.

17 Bhalla M, Turcois N, V A. Cystic fibrosis: scoring system with thin-section CT. Radiology 1991; 179:783-8.

18 Statistics New Zealand. NZ standard classification of ethnicity 1996 (1996).

19 Statistics New Zealand. New Zealand Census 2001 (2003).

20 Polgar G, Promadhat V. Pulmonary function testing in children: techniques and standards. Philadelphia: WB Saunders, 1971.

21 Wesley AW, Stewart AW. Cystic fibrosis in New Zealand: incidence and mortality. NZ Med J 1985;98:321-3.

22 Grant CC, Scragg R, Tan D, et al. Hospitilization for pneumonia in children in Auckland, New Zealand. J Paed Child Hlth 1998;34:355-9.

23 Grant CC, Pati A, Tan D, et al. Ethnic comparisons of disease severity in children hospitalized with pneumonia in New Zealand. J Paed Child Hlth 2001;37:32-7.

24 Wesley AW, Smith PA, Elliott RB. Experience with neonatal screening for cystic fibrosis in New Zealand using measurement of immunoreactive trypsinogen. Aust Paed J 1989;25:151-5.

25 Gazarian M, Williams K, Elliot $E$, et al. Evaluation of a national surveillance unit. Arch Dis Child 1999;80:21-7.

26 Eastham KM, Fall AJ, Mitchell $L$, et al. The need to redefine non-cystic fibrosis bronchiectasis in childhood. Thorax 2004;59:324-7.

27 Public Health Commission. The health of Pacific Islands People. Wellington: Public Health Commission, 1994.

28 New Zealand Ministry of Health. Pacific Island health information. Wellington: Ministry of Health, 1996. 